\title{
Epistemic Injustice and Collective Wrongdoing: Introduction to Special
}

\section{Issue}

\author{
Melanie Altanian (University College Dublin) and Nadja El Kassar (Freie \\ University Berlin)
}

(This article is published online in Social Epistemology, https://doi.org/10.1080/02691728.2020.1843199; please use the published version for quotations and page numbers.)

\begin{abstract}
In this introduction to the special issue "Epistemic Injustice and Collective Wrongdoing" we show how the eight contributions examine the collective dimensions of epistemic injustice. First, we contextualize the articles within theories of epistemic injustice. Second, we provide an overview of the eight articles by highlighting three central topics addressed by them: i) the effects of epistemic injustice and collective wrongdoing, ii) the underlying epistemic structures in collective wrongdoing, unjust relations and unjust societies, and iii) the remedies and strategies of resistance to epistemic injustice. We close by pointing to connections and issues that may motivate further research.
\end{abstract}

Epistemic injustice is often discussed with respect to individuals. But it is not limited to individuals. Most often, individuals experience epistemic injustice because they are members of particular groups and these groups, in turn, also experience epistemic injustice. Indigenous peoples experiencing radical testimonial injustice and hermeneutical injustice in their interaction with courts, prison inmates having their emergency calls systematically silenced, Armenian testimony about the Armenian genocide being oppressed - these are but some instances in which groups experience collective epistemic injustice. The authors in this special issue on Epistemic Injustice and Collective Wrongdoing examine these collective dimensions of epistemic injustice. Their works evince that we cannot fully understand some of the collective wrongdoing that groups experience unless we employ the conceptual tools of theories of epistemic injustice and affiliated theories. Notably, theories of epistemic injustice are not limited to Miranda Fricker's (2007) powerful account of epistemic injustice and its two basic forms, testimonial and hermeneutical injustice, but include further accounts and re- 
conceptualizations provided, for example, by Kristie Dotson (2011), Gaile Pohlhaus Jr. (2012), José Medina (2013), Amandine Catala (2015), Katherine Jenkins (2017), Jennifer Lackey (2020) and many others. Moreover, the contributors show how theories of epistemic injustice evolve when applied to cases of collective wrongdoing. Theory and social reality are mutually connected. Finally, the authors strengthen the bridges between theories of epistemic injustice, speech act theory and critical theory by showing how the theories are complementary in analyses of epistemic injustice.

The articles thus bring normative epistemological theorizing into social and political reality. The authors employ empirically informed, applied, analytical and critical epistemological approaches in order to analyse various forms of epistemic injustice that result from socially and politically nonideal conditions due to past or ongoing collective wrongdoing. At the same time, these approaches point to individual and collective ways of resistance to epistemic injustice. They do this most productively when they engage with real instances of collective wrongdoing, such as genocide, war crimes, or rape culture, and the marginalization and oppression of communities. Most of the authors in this special issue have chosen the method of engaging with real-life instances of collective wrongdoing, and their articles reveal much about the epistemic nuances of collective wrongdoing.

For example, authors discussing the case of genocide have shown that such collective wrongdoing often results from and is a means to sustain socially dominating institutions (cf. Theriault 2009). If the accompanying genocidal epistemology (or 'ideology', cf. Oranl, this issue) that facilitates genocide is not properly addressed and coped with afterwards, it leads to sustained oppression of the (former) victim group (cf. Altanian, this issue). Group knowledge and knowledge (or ignorance) about groups can be used as the driving forces of domination and oppression when they normalize unjust power relations between social groups. But group knowledge can also be the driving force of resistance and restoration, which gives rise to crucial questions: When do collective epistemologies become perniciously distorted such that 
they give rise to epistemic injustice? And under what conditions can collective epistemologies ameliorate social conditions, become a form of resistance and help work towards epistemic justice? These are some of the questions that the authors in this special issue address.

This special issue consists in eight articles based on earlier papers presented at the workshop 'Epistemic Injustice in the Aftermath of Collective Wrongdoing', which took place December 6-7, 2019, at the University of Bern, Switzerland. The workshop included presentations of, besides the organizer Melanie Altanian, invited guests Jennifer Lackey, Gaile Pohlhaus Jr., José Medina and Imge Oranlı, as well as five participants accepted through abstract submission (double blind review). Each of the articles contributed to this special issue went through a combination of both double blind peer review and open peer review by the original commentators from the workshop. While some contributions focus specifically on identifying epistemic injustice and its structural causes in contexts of racist and sexist domination and oppression, others focus on epistemic resistance and propose ways to ameliorate injustice. What unites them is the underlying conviction that ethics and epistemology are intertwined in crucial ways and that both ethics and epistemology have to be employed in understanding and fighting structures of domination and oppression: first, by attending to the pernicious epistemologies that both enable and sustain them; second, by pointing out the strengths and powers of collective epistemic resistance.

Breno Santos in 'Echo Chambers, Ignorance and Domination' argues that echo chambers are infused by ignorance and function as tools of hermeneutical domination. Imge Oranlı in 'Epistemic Injustice from Afar: Rethinking the Denial of Armenian Genocide' presents an interdisciplinary study of genocide denialism and its ideological roots in the case of the Armenian Genocide. Melanie Altanian in 'Genocide Denial as Testimonial Oppression' explicates genocide denial as a substantive practice of ignorance that gives rise to testimonial oppression. Dina Townsend and Leo Townsend in 'Epistemic Injustice and Indigenous Peoples in the Inter-American Human Rights System' show how the well-intended right to 
consultation and right to property foster epistemic objectification of Indigenous peoples and hermeneutical injustice. Seunghyun Song in 'Denial of Japan's Military Sexual Slavery and Responsibility for Epistemic Amends' argues that agents can be responsible for past epistemic injustice as well as liable for making amends for this past and present epistemic injustice. Hilkje Hänel in 'Who's to Blame? Hermeneutical Misfire, Forward-Looking Responsibility, and Collective Accountability' explicates how sexist ideology yields hermeneutical gaps and distorts conceptions of sexual violence, requiring a forward-looking account of responsibility oriented towards redressing structural injustice. José Medina in 'Agential Epistemic Injustice and Collective Epistemic Resistance in the Criminal Justice System' reveals underlying structures of agential epistemic injustice in the US criminal system and develops conditions of collective epistemic resistance against such injustice. And lastly, Nadja El Kassar in 'The Powers of Individual and Collective Intellectual Self-Trust in Dealing with Epistemic Injustice' introduces collective and individual intellectual self-trust as means for obstructing the effects of epistemic injustice and engaging in resistance to epistemic injustice and collective wrongdoing.

In the remainder of this introduction, we provide a more detailed overview of the eight articles by highlighting three central topics addressed by them: i) the effects of epistemic injustice and collective wrongdoing, ii) the underlying epistemic structures in collective wrongdoing, unjust relations and unjust societies, and iii) the remedies and strategies of resistance to epistemic injustice.

\section{Topic 1: The Effects of Epistemic Injustice and Collective Wrongdoing}

Collective wrongdoing does not just consist in physical or psychological harm, but also encompasses specifically epistemic harms. For example, Seunghyun Song shows that both the Japanese government and historians have silenced women survivor's testimony on their experiences of military sexual slavery during World War II and instead propagate collective 
ignorance, or what Song calls 'false-knowledge,' about the past injustice. Employing Fricker's account of epistemic injustice, Song argues that the unjust epistemic exclusion and marginalization of survivors from the official account of Japan's military sexual slavery have both caused and continue to cause epistemic harm. In particular, the survivors experience testimonial injustice when their testimony about Japan's military sexual slavery is not treated as a contribution to knowledge production; and they experience hermeneutical injustice when Japan rejects the term 'sexual slavery' to describe the women's situation. Such injustice is a form of dehumanization, hence a violation of the women's dignity. Due to such testimonial and hermeneutical injustice, survivors are still awaiting accountability and proper acknowledgment of their experiences of injustice. Moreover, due to the stigma of shame attached to experiences of sexual violence, survivors have only started to testify their experiences publicly 30 years later. By speaking up and giving testimony, they try to resist their epistemic exclusion in both Korea and Japan.

The case of genocide denialism regarding the Armenian genocide of 1915-16 reveals further practices of epistemic injustice. Relying on Fricker's account of testimonial injustice, Imge Oranlı argues that Armenians face testimonial injustice in Turkey due to a negative epistemic identity prejudice attached to their identities. They thereby face systematic credibility deficits, first and foremost due to their representation as 'traitors' in the collective social imagination. Moreover, their experiences and narratives are systematically silenced through educational institutions because they are seen as a threat to the official, collective Turkish memory supported by the state and its institutions.

Melanie Altanian's article reveals how systematic testimonial injustice after genocide turns into testimonial oppression. More specifically, Altanian argues that genocide denialism creates conditions that coerce Armenians into silencing themselves about the experiences of their people since they persistently experience unwarranted resistance on behalf of their (Turkish) interlocutors - presenting a case of what Kristie Dotson (2011) calls 'testimonial 
smothering'. Under circumstances of genocide denialism, Armenians experience persistent failures in testifying to genocide because their interlocutors misunderstand their speech. Again, the state, its institutions as well as individuals collaborate in manufacturing a version of history that fosters substantive, collective ignorance about both the genocide as well as Armenians. Altanian argues that genocide denialism thereby undermines trust relations crucial for testimony. It also systematically deprives potential testifiers of valuable epistemic recognition. Systematic deprivation of such epistemic recognition can undermine their capacities of (self-) comprehension, reasoning and of making relevant epistemic contributions to actively resist their oppression. It ultimately coerces them to act in ways that further their own oppression.

Dina Townsend and Leo Townsend, in their study of interactions of Indigenous peoples with the Inter-American Court and Commission on Human Rights, show how radical testimonial injustice leads to epistemic objectification and silencing. Even well-intentioned strategies such as a right to consultation and a right to property instated by the Inter-American Court and Commission on Human Rights involve serious epistemic injustice. This is because the testimony of the Indigenous peoples is not taken up as a description of the environment but reduced to a mere worldview. They are not accepted as experts and informants contributing to knowledge production but degraded to mere sources of information. They are thereby treated as epistemic objects rather than epistemic subjects. Townsend and Townsend emphasise that Indigenous peoples also face 'hermeneutical domination' (Catala 2015) since they are in a situation in which the dominant group's hermeneutical resources are actively imposed onto them as a non-dominant group. In the case at hand, the conceptual vocabulary of 'property' is imposed by the legal institution on the Indigenous peoples. They are thus unable to achieve legal intelligibility when articulating their relations to their land.

Breno Santos points to another case of hermeneutical domination brought about by the Brazilian government's propagation of a 'gender ideology' conspiracy. Not only does this 
attack the epistemic credentials of politically left-wing citizens, but more seriously, they put LGBTQ+ people at heightened risk. Even though Altanian, Oranlı and Song do not explicitly use this term in their contributions, hermeneutical domination also occurs in the situation of Armenians in Turkey as well as the survivors of Japan's military sexual slavery who face systematic denial. Such domination is a key variety of epistemic injustice. (We will return to the structures underlying hermeneutical domination in Topic 2.)

Combining speech act theory and Jennifer Lackey’s theory of agential testimonial injustice, José Medina argues that the American criminal justice system is designed to systematically and unfairly constrain the epistemic agency of detained subjects. Specifically, Medina suggests three ways in which prison inmates are subjected to agential epistemic injustice: First, they are only believed when they are deprived of epistemic agency (corresponding to Lackey's analysis of false confessions [2020]). Secondly, their exercise of epistemic agency is nullified or diminished by the cancelling ('illocutionary silencing') or subversion ('illocutionary flipping') of the force of their speech acts, making it virtually impossible for detainees to emit emergency calls. Medina introduces Luvell Anderson's concept of 'illocutionary flipping' to capture this treatment that the inmates face: 'a speaker sets out to perform one speech act—while being entitled to perform it in that context and use the conventionally appropriate words, tones, and gestures — but the kind of uptake given constitutes an entirely different act' (Anderson 2017, 144). And thirdly, the prison inmates receive no uptake at all or merely negative and inhibitory uptake; the consequences of the subject's speech acts are thereby rendered 'ineffectual and self-undermining' (Medina, this issue). These are instances of what Medina calls 'perlocutionary flipping' or 'perlocutionary silencing'. Such epistemic silencing alienates subjects from their epistemic agency by blocking or subverting the intended consequences of their communicative acts.

The effects of epistemic injustice do not just affect clearly delineated groups and their members. We also find them in more dispersed groups, such as survivors of rape and sexual 
violence. In her contribution, Hilkje Hänel uncovers the workings of sexist ideology on survivors and society in general in their understanding of and reactions to rape. Survivors and perpetrators face hermeneutical gaps that distort their conception of sexual violence - and yet do not exonerate the perpetrators of sexual violence from their responsibility. These gaps affect society in general, a very far-reaching effect of epistemic injustice. But while these gaps lead to 'hermeneutical misfire' in the case of perpetrators, survivors of rape and sexual violence suffer hermeneutical injustice.

Nadja El Kassar points to the largely overlooked effects of epistemic injustice and collective wrongdoing on individual and collective intellectual self-trust. Persistent epistemic injustice undermines individual and group trust in their own observations and beliefs, their ability to contribute to epistemic practices as epistemic agents. These effects harm both individuals and their intellectual self-trust as well as the intellectual self-trust of marginalized or oppressed groups. Thereby their abilities to make sense of themselves and the world are affected. Yet, intellectual self-trust is not just an object of epistemic injustice; as El Kassar argues, it is also key to obstructing and resisting epistemic injustice (Topic 3).

All of the above effects of epistemic injustice and collective wrongdoing harm the groups and individual group members. The effects are exacerbated by unjust structures, inequality as well as psychological and physical effects of the wrongdoing suffered, such as isolation, loss of intellectual confidence, and loss of a sense of identity. This special issue also aims to understand the underlying structures of these effects. Most of these structures are hidden, but all of the articles uncover pertinent structures that constitute and perpetuate collective wrongdoing. Understanding those structures is a key step in formulating and realizing remedies and resistance to epistemic injustice, including reparations. 


\section{Topic 2: Underlying Epistemic Structures in Collective Wrongdoing, Unjust Relations and Unjust Societies}

The epistemic injustices identified in these contributions all have their roots in particular unjust institutional and/or structural background conditions that have immediate epistemic implications. For example, as Medina illustrates, particular institutional processes and practices within the American criminal justice system prompt unfair constraints on detainees' epistemic agency. First, practices of coercion and manipulation are used to annihilate or subvert the epistemic agency of detainees and thereby extract false confessions, which are then given credibility excess (cf. also Lackey 2020). Second, detainees' speech acts concerning medical emergencies are widely discredited and distorted; their emergency calls are nullified ('illocutionary silencing') or given the wrong kind of uptake because they are understood as performing another kind of speech act altogether. For example, an emergency call is understood and treated as a way of seeking special treatment, a way of distracting or overburdening officers, or a way of overstating or exaggerating safety concerns. Third, there are systematic dysfunctions in processing, responding to and acting upon the numerous filed grievances and informal complaints of detainees. Medina thereby highlights ways in which some of the inmates' vital speech acts fail because the appropriateness conditions are systematically distorted in the American prison context.

In the case of the treatment of Indigenous communities in the Inter-American Human Rights system, focusing inter alia on the Court case of the Sarayaku people, Townsend and Townsend show that the unjust epistemic structures reach back to the very establishment of the conceptual repertoire of the Human Rights system. Given the hermeneutical marginalization and general epistemic neglect of Indigenous communities from discursive practices in which the conceptual vocabulary of international law has been developed, their ability to articulate their relation to land is stifled because they are forced to use the unfitting conceptual language of 'property'. Moreover, the Court treats their claims as expressions of 
their 'worldview' and 'cultural identity', in contrast to the testimonies of environmental scientists that are recognized as straightforward assertions about the likely impacts of the proposed activities on the environment in question. The Court thus epistemically objectifies the Sarayaku People, i.e., does not consider them credible informants with respect to the nature of the environment but treats them as mere sources of information about the community's culture or worldview. This interpretive practice can result in further disadvantages for the Sarayaku people: actors seeking to extract oil from the lands in question are unlikely to consider the impact of such activities on the environment as it has been described by the community because the community's description is treated as a mere worldview rather than a knowledge claim. As Townsend and Townsend point out, these conditions give rise to a 'radical communicative dysfunction' (Fricker 2007, 140) in which the Inter-American Court and Commission on Human Rights silence the Sarayaku people by not giving their testimony any epistemic consideration at all.

Unjust power relations are also at work in societal contexts imbued by sexist or racist ideology. Such ideologies are used to legitimize and maintain a socially and politically unjust status quo in a given society, in that they not only affect the distribution of epistemic and other goods, but also patterns of epistemic recognition accorded to differently socially situated members of society (Altanian, this issue). Dominant situatedness usually goes along with various kinds of privileges and excesses, such as credibility excess or privileged access to hermeneutical participation (Oranlı, Medina, Santos, this issue). Marginalized situatedness, in turn, goes along with various unjust disadvantages and losses, such as credibility deficits and unwarranted exclusion from hermeneutical participation (Song, Hänel, Townsend and Townsend, this issue). Ultimately, however, such ideologies and conditions of domination and oppression present disadvantages for all members of society. As Hänel argues, the hermeneutical gaps generated by hermeneutical marginalization can render all members of society hermeneutically impoverished. They can prevent members of the dominant group 
from comprehending their actions, thus leading to hermeneutical misfiring. From the point of view of injustice, however, for those at the losing end of hermeneutical misfiring - for example, survivors of rape or domestic abuse - the quality of suffering goes deeper: in addition to experiencing physical abuse, they are systematically thwarted in their attempts to render these experiences intelligible to themselves and others, in order to repair the initial harms as well as seek justice and repair.

Hermeneutical marginalization within societies structured by sexist, racist or other ideologies of social inferiority and superiority is also constitutive of hermeneutical domination that we have already mentioned above. In contrast to Fricker's structural notion of hermeneutical injustice on the basis of hermeneutical marginalization, hermeneutical domination arguably points to a more active form of hermeneutical injustice that is enforced by the dominant group and that cannot be meaningfully contested by those at the losing end. These practices are often complemented by wilful hermeneutical ignorance (cf. Pohlhaus Jr. 2012). In addition, unlike structural epistemic injustice and more specifically, structural hermeneutical injustice, which is characterized by a structural identity prejudice operating in the collective hermeneutical resource (Fricker 2007, 155), hermeneutical domination shifts the focus to the dominant group's power to shape epistemic practices to the advantage of dominant situatedness and at the expense of marginalized or subordinate situatedness. It therefore intersects testimonial and structural hermeneutical injustice: due to the dominator's power to impose an epistemically inferior status to subordinate groups that denies them equal epistemic status or gives them an unwarranted credibility deficit, their contributions to the dominant public discourse around the particular practices and experiences are systematically dismissed.

As Santos argues in his article, hermeneutical domination can also be manifested in 'echo chambers'. Santos reflects on Nguyen's account (2020) of echo chambers, according to which they are epistemic communities in which members share belief-forming methods, 
reasoning tools, informational resources, etc. In a sense, they are the result of our dependency on a division of epistemic labour, i.e., our epistemic dependency on others. However, an echo chamber has a problematic feature: it is an epistemic community in which relations of dependency are exclusionary by design. In an echo chamber, epistemic inputs from nonmembers are actively rejected or excluded in favour of internal inputs (inputs from members). This exclusion is done by the systematic manipulation and discrediting of outside epistemic sources. Thus, echo chambers are epistemic communities - or 'social epistemic structures' in which members are convinced to distrust non-members and in which, consequently, 'other relevant voices have been actively discredited' (Nguyen 2020, 142). Such echo chambers resemble what social epistemologists have called 'substantive ignorance' or structural conceptions of ignorance such as 'active ignorance' and 'willful hermeneutical ignorance' (Alcoff 2007, Mills 2007, Pohlhaus Jr. 2012, Medina 2013, Fricker 2016). Hence, Santos suggests that in order to account for the epistemically deleterious effects of echo chambers properly, a proper reading of Nguyen's concept of echo chamber should make use of the notion of structural ignorance.

Most contributions to this issue show how the epistemic injustices identified result from epistemic structures that promote ignorance in some form or another, at the institutional, the structural and the individual level: ignorance about social reality, ignorance about certain subject matters, groups, or injustices. For example, the contributions deal with ignorance about historical genocide (Oranll, Altanian), ignorance about wartime systems of sexual slavery (Song), ignorance about rape culture (Hänel), ignorance about climate change or gender discrimination (Santos). Such ignorance is both generated and sustained by individual and institutional agents and structures with the aim to maintain an unjust status quo. Hence, they signify not only states but practices of ignorance that are a product of structural conditions that produce identities, social locations and modes of belief formation which, in some cases, can become epistemically disadvantageous or defective (see Alcoff 2007, 40). A 
practice of ignorance, or ignorant agency, is guided by particular cognitive norms and policies: it presents motivated ignorance that enables or even requires members of certain groups to know and understand the world in systematically distorted ways. (cf. Mills 1997) For example, a racist socio-political order makes its way into epistemic practices and structures by leading to a 'kind of collective interested or motivated cognitive bias in what social interpretations and/or evidence for such interpretations a racially dominant group attends to and integrates into the rest of their beliefs and deliberations' (Fricker 2016, 270).

This is what Mills (2017) and others have referred to as 'racial ideology', the idea that racial privilege has immediate epistemic effects insofar as it also brings about epistemic privilege. According to Mills, racial domination is also 'manifest cognitively, in belief systems, conceptual frameworks, and normative assumptions'. Here, the role of ideology is to ‘justify, rationalize, legitimize, and/or obfuscate wrongful social domination' $(2017,102-$ 104). Oranlı adopts Mills' account of ideology to show how the ideology of Turkism functions similarly to obfuscate the reality of 'Turkish' domination of Armenians and other non-'Turkish' minorities. Using Medina’s (2013) notion of active ignorance, she also illustrates how epistemic privilege that goes along with racially dominant, i.e., 'Turkish' situatedness gives rise to various epistemic vices on behalf of 'Turkish' individuals, rendering it difficult for 'Turkish' society to take productive steps towards the recognition of the Armenian genocide.

Similar to racial ideology, Hänel argues that sexist ideology also presents 'a social structure, constituted by ritualized social practices, and rationalized by a coherent cultural framework that organizes social agents into binary gender relations of domination and subordination' (Hänel 2018, 900). Hänel shows in her contribution how such a social structure systematically distorts our conceptions of sexual violence, i.e., constrains our epistemic tools for interpreting such actions; not only for women and gender non-conforming people 
experiencing sexual violence, but also for members of the male dominating group perpetrating it - they are subject to what Hänel calls 'hermeneutical misfiring'.

The term 'ideology', however, can also be utilized to dismiss legitimate belief systems, conceptual frameworks, and normative assumptions that allegedly seek to identify and resist social injustice. Santos illustrates this by reference to the Brazilian government's propagation of a 'gender ideology' that seeks to 'demolish "traditional values" by imposing the notion that there are no defined genders or that everyone is gay [...]' and that ' $[\ldots]$ wanted to make it illegal to be a straight cisgender man in Brazil'. Such misuses aim to obscure actual power relations and they undermine the conceptual purpose of concepts like 'ideology', which is to bring to light the epistemic functioning of unjust power relations.

The problem of conceptual misuse is also discussed in Altanian's analysis of genocide denialism. There, she uses the idea of distortions of normativity at the level of its social articulation (cf. Pauer-Studer and Velleman 2011) to show how institutional processes and practices of denialism seek to distort not only morally relevant facts about social reality, such as unjust material conditions and social power relations, but also normative concepts such as genocide in order to distort the meaning of genocide recognition itself and to justify genocide denialism (or genocide 'skepticism'). This establishes conditions of pervasive ignorance that render communication on genocide persistently dysfunctional, unjustly constraining Armenians from testifying to - in the sense of communicating - experiences of injustice and thereby contesting dominant understandings.

\section{Topic 3: Remedies and Resistance}

A third central topic addressed by some of the articles in this special issue are strategies of resistance and remedies against collective wrongdoing and epistemic injustice. El Kassar argues that collective intellectual self-trust, a largely understudied optimistic disposition of groups towards their beliefs and perception, is a crucial tool for obstructing the effects of 
epistemic injustice as well as for resisting epistemic injustice. Epistemic injustice excludes disadvantaged individuals and groups from epistemic practices, disrupts their epistemic agency and is very likely to cause self-doubt and loss of trust in one's intellectual capacities. Collective intellectual self-trust enables disadvantaged groups to block these effects of epistemic injustice: they can trust the way they see things, they can trust their beliefs. For example, patients who suffer from chronic illness that are difficult to diagnose gain support from testimonials of other patients with chronic illnesses and they are in turn able to take up the testimonials in the right way. Victims of the Armenian genocide can develop collective intellectual self-trust in their experiences of the genocide and their views on the genocide, thus blocking the self-doubt induced by the dominant, oppressive Turkish narrative.

Interestingly, intellectual self-trust and other remedies, such as acknowledgment, can be severely harmed by epistemic injustice and, at the same time, are also crucial tools for remedying epistemic injustice and collective wrongdoing. This double role may explain why resistance against epistemic injustice and collective wrongdoing and remedies are often difficult to implement successfully.

Collective intellectual self-trust also fosters individual intellectual self-trust, an optimistic disposition towards one's own intellectual capacities. And both individual and collective intellectual self-trust are essential for acts of resistance against epistemic injustice: speaking up against the injustice, engaging in what Medina calls 'epistemic activism', e.g., inmates collecting their grievances and presenting them in an anonymous way via the 'First Five Grieving Committee' (Medina, this issue), engaging in epistemic resistance in the form of poems and novels (Medina 2013), or writing an epistemology of incarceration (The LoCI and Wittenberg University Writing Group 2016, McHugh 2017). Such collective epistemic activism can also extend to non-oppressed allies, e.g., inmates being supported by nonincarcerated family members, journalists, NGOs, or Armenians being supported by nonArmenians in getting the genocide acknowledged. This broad basis blocks the harmful effects 
of epistemic injustice and epistemic oppression and, as Medina emphasizes, it 'protect[s] and augment[s]' the epistemic agency of the disadvantaged and oppressed subjects and groups (Medina, this issue).

As Hänel argues, using the framework of political responsibility by Iris Marion Young, the dominant community can and must also engage in changing the conditions of an unjust and even violent society, e.g., in the case of rape culture. They are collectively accountable for preventing future harm. '[I]t is the community's responsibility to prevent future harm, to help the victim in their needs, and to help the perpetrator to develop skills to prevent further harm' (Hänel, this issue), thus changing the perspective of the perpetrator of sexual violence as well as communal structures that enforce sexist ideologies. Importantly, the perpetrator is not discharged from their responsibility for their actions. They need to change their perspective and acknowledge the harm they have committed, but communities need to complement these transformations since the problems are not limited to the perpetrator. Such collective accountability also translates into structural remedies against epistemic injustice that need to complete most strategies against epistemic injustice (cf. Anderson 2012, Townsend and Townsend this issue).

'Acknowledgment' of the harm done also combines individual and collective action against epistemic injustice. Song conceives of acknowledgement as making epistemic amends, and she argues that 'acknowledgment has three steps: a responsible agent's thorough recognition of 1) what the injustice entailed for the victims, 2) that the injustice should not have occurred, followed by his or her 3) genuine commitment to not repeat the injustice' (Song, this issue). In the case of military sexual violence committed by Japan and Japanese soldiers, such acknowledgment is required not only from the Japanese government but also by individuals such as the historian Hata Ikuhiko, whose academic work denies that the women were subjected to military sexual slavery. They need to make epistemic amends for their epistemic actions of denial. 
Turning to Fricker's approach of virtues as remedies against epistemic injustice, Townsend and Townsend introduce 'communicative justice' as a virtue specifically covering the communicative nature of epistemic injustice.

Communicative justice means not allowing prejudicial views about a speaker, including views about the speaker's epistemic authority in certain domains, to distort one's perception of what a speaker is up to with her words - which communicative acts she means to perform (Townsend and Townsend, this issue).

Similarly, Altanian highlights in the context of genocide testimony that speakers trust their audience to exercise testimonial competence (cf. Dotson 2011, 245). This means that hearers ought to demonstrate to the speaker that they will find proffered testimony accurately intelligible, that they 'do what it takes to hear what she intends to communicate' (Dormandy 2020, 256), and that they respect any emotional or practical risks to which testimony might expose the speaker (257). Absent such communicative competence on the hearers' part, speakers will likely be coerced to silence themselves or continue to be misunderstood.

\section{Conclusion and Outlook}

By discussing actual cases of epistemic injustices and collective wrongdoing, the authors of this special issue demonstrate the many faces of theories of epistemic injustice. They show how epistemic injustice is manifested in communication, thus calling for tools from speech act theory and communication theory. They reveal how epistemic injustice is fuelled by ignorance, both wilful and blameworthy ignorance and non-blameworthy ignorance, thus connecting closely with epistemologies of ignorance. Collective wrongdoings attest to the communal nature of epistemic injustice; it is not just an individual perpetrator who commits epistemic injustice; rather, (epistemic) communities, ideologies, structures and worldviews are also constitutive of epistemic injustice. This broadened perspective also introduces a temporal dimension to epistemic injustice: epistemic injustice is not limited to the time of the 
epistemic injustice experienced, e.g., when the testimony of the Kichwa People of Sarayaku in court is not recognized as a contribution to an epistemic practice or when witness testimony about the Armenian genocide is rejected and oppressed. Rather, it also extends to the times before and after the testimony and spreads to ancestors and descendants of the groups who face the epistemic injustice. Armenians today who did not experience the genocide first-hand are still unable to express their views about the genocide in Turkey, and they engage in resistance to the oppressive practices even though it was their elders who directly experienced the genocide. Similarly, the victims of the Japanese military sexual slavery during World War II are supported by their descendants and younger allies speaking up and calling for epistemic amends. Fighting epistemic injustice thus is an instance of transgenerational justice.

The articles in this special issue contribute to a more detailed understanding of epistemic injustice in collective wrongdoings. By presenting analyses of the effects and structures of collective wrongdoings and epistemic injustice, the authors motivate further analyses of epistemic injustice in other collective wrongdoings and inspire research into additional strategies of resistance against them.

\section{References}

Alcoff, L. M. 2007. “Epistemologies of Ignorance: Three Types.” In Race and Epistemologies of Ignorance, edited by S. Sullivan and N. Tuana, 39-57. New York: State University of New York Press.

Anderson, E. 2012. "Epistemic Justice as a Virtue of Social Institutions.” Social Epistemology 26 (2): 163-173. https://doi.org/10.1080/02691728.2011.652211.

Anderson, L. 2017. "Epistemic Injustice and the Philosophy of Race.” In The Routledge Handbook of Epistemic Injustice, edited by I. J. Kidd, J. Medina, and G. Pohlhaus Jr., 139-148. New York: Routledge. https://doi.org/10.4324/9781315212043.ch12.

Catala, A. 2015. “Democracy, Trust, and Epistemic Justice.” The Monist 98 (4): 424-440. https://doi.org/10.1093/monist/onv022.

Dormandy, K. 2020. “Exploitative Epistemic Trust.” In Trust in Epistemology, edited by K. Dormandy, 241-264. New York: Routledge. 
Dotson, K. 2011. "Tracking Epistemic Violence, Tracking Practices of Silencing." Hypatia 26 (2): 236-257. https://doi.org/10.1111/j.1527-2001.2011.01177.x.

Fricker, M. 2007. Epistemic Injustice: Power and the Ethics of Knowing. Oxford: Oxford University Press.

Fricker, M. 2016. "Epistemic Injustice and the Preservation of Ignorance." In The Epistemic Dimensions of Ignorance, edited by R. Peels, 160-177. Cambridge: Cambridge University Press.

Hänel, H. C. 2018. "What Is a Sexist Ideology? Or: Why Grace Didn’t Leave.” Ergo, an Open Access Journal of Philosophy 5 (34): 899-921. https://doi.org/10.3998/ergo.12405314.0005.034.

Jenkins, K. 2017. "Rape Myths and Domestic Abuse Myths as Hermeneutical Injustices." Journal of Applied Philosophy 34 (2): 191-205. https://doi.org/10.1111/japp.12174.

Lackey, J. 2020. “False Confessions and Testimonial Injustice.” Journal of Criminal Law and Criminology 110 (1): 43-68.

McHugh, N. 2017. "Epistemic Communities and Institutions." In The Routledge Handbook of Epistemic Injustice, edited by I. J. Kidd, J. Medina, and G. Pohlhaus Jr., 270-278. New York: Routledge.

Medina, J. 2013. The Epistemology of Resistance: Gender and Racial Oppression, Epistemic Injustice, and Resistant Imaginations. Oxford: Oxford University Press.

Mills, C. 1997. The Racial Contract. Ithaca: Cornell University Press.

Mills, C. 2007. "White Ignorance.” In Race and Epistemologies of Ignorance, edited by S. Sullivan and N. Tuana, 11-38. New York: State University of New York Press.

Mills, C. 2017. Black Rights/White Wrongs: The Critique of Racial Liberalism. New York: Oxford University Press.

Nguyen, C. T. 2020. “Echo Chambers and Epistemic Bubbles.” Episteme 17 (2): 141-161. https://doi.org/10.1017/epi.2018.32.

Pauer-Studer, H. and J. D.Velleman. 2011. "Distortions of Normativity." Ethical Theory and Moral Practice 14 (3): 329-356. https://doi.org/10.1007/s10677-010-9246-7.

Pohlhaus Jr., G. 2012. "Relational Knowing and Epistemic Injustice: Toward a Theory of Willful Hermeneutical Ignorance.” Hypatia 27 (4): 715-735. https://doi.org/10.1111/j.1527-2001.2011.01222.x.

The LoCI and Wittenberg University Writing Group. 2016. "An Epistemology of Incarceration: Constructing Knowing on the Inside." PhiloSOPHIA 6 (1): 9-25. https://doi.org/10.1353/phi.2016.0005. 
Theriault, H. C. 2009. “Genocide, Denial, and Domination: Armenian-Turkish Relations from Conflict Resolution to Just Transformation." Journal of African Conflicts and Peace Studies 1 (2): 82-96. https://doi.org/10.5038/2325-484X.1.2.5. 